\title{
The Relationship Between Brain Natriuretic Peptide (NT-proBNP) Levels and Diastolic Heart Failure in Patients With COVID-19
}

Naghmeh Ziaie

Babol University of Medical Science

Khadijeh Ezoji

Babol University of Medical Science

Seyedeh Golnaz Ziaei

Babol University of Medical Science

Mohammad Chehrazi

Babol University of Medical Science

Parviz Amri Maleh

Babol University of Medical Science

Roghayeh Pourkia

Babol University of Medical Science

Shahram Seyfi ( $\nabla$ ficu_ss@yahoo.com )

Babol University of Medical Science

\section{Research Article}

Keywords: NT-proBNP, COVID-19, diastolic dysfunction

Posted Date: September 27th, 2021

DOl: https://doi.org/10.21203/rs.3.rs-868043/v1

License: (9) (i) This work is licensed under a Creative Commons Attribution 4.0 International License.

Read Full License 


\section{Abstract}

Background: Diastolic dysfunction has been reported in patients with COVID-19. Due to the role of Nterminal pro-brain natriuretic peptide (NT-proBNP) in the diagnosis of heart failure, this study investigated the relationship between serum NT-proBNP levels and diastolic heart failure in COVID-19 patients.

Methods: This descriptive-analytical study was performed at Ayatollah Rouhani Hospital in Babol. Fiftyfour patients with confirmed COVID-19 diagnosis who were admitted to the ICU were included in the study. The primary outcome was the relationship and predictive role of NT-proBNP and diastolic heart failure in patients with severe SARS-COV-2 infection. Patients with pro BNP $>125 \mathrm{pg} / \mathrm{mL}$ underwent echocardiography and the relationship between echocardiographic indices and NT-proBNP was assessed as a secondary outcome.

Results: Our study showed that plasma NT-proBNP levels in patients with increased diastolic dysfunction were associated with disease severity. It was also found that the cut-off point of NT-proBNP $=799 \mathrm{pg} / \mathrm{mL}$ could be a predictor of diastolic dysfunction grades two and three. In this study, patients with a serum NTproBNP level equal or above 799 had 37 times higher chance of having diastolic dysfunction than those with a serum NT-proBNP level below 799. Patients with NT-proBNP above 556 had RV_EA> 2 in echocardiography, indicating increased right-sided filling pressures.

Conclusion: Despite the confounding factors in the interpretation of the pro BNP level in COVID-19, its level can be used to estimate the presence of high-grade diastolic heart failure on the left and right sides of the heart and the presence of high filling pressures. Lower levels of NT-proBNP are associated with right-sided diastolic failure.

\section{Background}

Since December 2019, the world has been experiencing a rapid outbreak of a newly discovered infectious disease. COVID-19 occurs primarily as an acute respiratory disease with interstitial and alveolar pneumonia, but can affect various organs such as the heart, kidneys, gastrointestinal tract, blood, and central nervous system (1). Microangiopathy, myocarditis, myocardial infarction or even heart failure have been reported in COVID-19 (2,3). A meta-analysis of 25 studies reported on non-COVID-19 pneumonia stated that cardiac complications were observed in a quarter of patients with COVID-19 being the most common (14\%) (4), but the incidence of heart failure in patients with COVID-19 and even other diseases caused by coronaviruses such as severe acute respiratory syndrome (SARS-CoV-1) and Middle East respiratory syndrome (MERS-CoV) have not received much attention.

A cohort study on 3080 confirmed COVID-19 patients who were followed up for 30 days showed an incidence of acute heart failure in $2.5 \%$ of these patients. The incidence and progression of heart failure in patients in this study were associated with a poorer outcome (5). The relationship between diastolic heart failure and COVID-19 has also been reported in the meanwhile. A study has reported an association between COVID-19 and diastolic heart failure, subclinical diastolic failure, or exacerbation of diastolic 
heart failure. Although case reports have described COVID-19 myocarditis leading to diastolic dysfunction, the most common heart failure during COVID-19 is subclinical diastolic dysfunction and the emergence of new diastolic dysfunction following SARS-CoV-2 infection (5).

The overlap of clinical signs and radiological manifestations of COVID-19 and HF is an undeniable obstacle to the correct diagnosis of these conditions $(6,7)$. Restrictive criteria for the use of non-invasive imaging tests such as echocardiography and the recommendation to use simple physical examinations recommended by the international scientific community make it difficult to diagnose heart failure in COVID-19 (6-9). The role of cardiac biomarkers such as N-terminal pro-brain natriuretic peptide (NTproBNP) is proved in the diagnosis of AHF in patients with shortness of breath and no previous history of $\mathrm{HF}$, especially if imaging techniques are not available or limited use is recommended, as is the case in COVID-19 pandemic (9). Of course, NT-proBNP has played a growing role in this area over the years.

NT-ProBNP is released from myocytes in response to increased cardiac wall stress and provides a strong independent prognostic value in patients with various cardiovascular diseases such as heart failure, acute coronary syndrome, aortic valve stenosis, and stable coronary involvement (10). NT-ProBNP in COVID-19 rises unpredictably in response to the criteria we have in heart failure due to hypoxia, sepsis, and inflammatory responses (11). Due to the limited role of echocardiography because of the close distance between the operator and the patient and the time it takes to obtain more accurate parameters in echocardiography, this study aimed to examine the predictive role of NT-proBNP in diastolic heart failure and its relationship with echocardiographic parameters in patients with COVID-19.

\section{Methods}

This cross-sectional descriptive study was performed on 52 adult patients with COVID-19 diagnosis hospitalized in the ICU of Rouhani Hospital in Babol from June 21 to September 21, 2020. All steps were followed according to the instructions of the Research Ethics Committee of Babol University of Medical Sciences, Babol, Iran (IR.MUBABOL.REC.1399.321). The primary outcome was the determination of the predictive role of NT-proBNP in the diagnosis of diastolic heart failure in patients with severe SARS-COV-2 infection. Inclusion criteria included patients with severe COVID-19 disease who were admitted to ICU and whose COVID-19 infection was confirmed by polymerase chain reaction (PCR) or a combination of clinical manifestations and chest CT scan, and patients whose level NT-proBNP in their plasma was measured to be above $125 \mathrm{pg} / \mathrm{mL}$. Echocardiography was performed for eligible patients.

Patients under 18, patients without NT-proBNP results, patients with malignant tumors, stroke or myocardial infarction, pregnant women, patients who died while being hospitalized or transferred to other hospitals were excluded from the study. Demographic and clinical information were reviewed and recorded by asking the patient questions and reviewing the patient file. For laboratory data, blood samples were collected and NT-proBNP was measured using fluorescence immunoassay (Triage ${ }^{\circledR}$ BNP; Alere). Patients with proBNP $<125 \mathrm{pg} / \mathrm{mL}$ underwent echocardiography by a cardiologist. Additional laboratory test results including blood count, renal function analysis, electrolytes, CRP, IL-6, and pre- 
calcitonin and D-dimer oxygen saturation level were also recorded. All clinical and laboratory data were collected within 24 hours after admission.

Items measured on echocardiography included: the size of the cardiac cavities in diastole, ejection fraction in systole on the right and left, right and left atrial size, systolic venous pressure, IVC diameter, pericardial effusion rate, diastolic function including $E$ and $A$ - wave velocity and the $E / A$ ratio and the $E / E$ tissue movement velocity on the right and left separately. Estimation of the severity of diastolic heart failure was calculated using the guidelines of the American Society of Echocardiography (12). Statistical analysis was performed by SPSS 22.0 (SPSS, Chicago, IL, USA). Data were presented as mean standard deviation, frequency (\%). Independent samples t-test and chi-square test in rank variables were used for intergroup comparison in continuous variables with normal distribution. The ROC curve was used to determine the "optimal" NT-proBNP cut-off point for predicting diastolic dysfunction and the Yuden index (Ref) method. Patients were classified into two groups due to the fact that their NT-proBNP level was higher or lower than this cut-off point, and the relationship between NT-proBNP level above the cut-off point and mortality was tested using chi-square test. Bilateral $\mathrm{P}<0.05$ was considered statistically significant.

\section{Results}

During the study period, data from 52 patients with COVID-19-confirmed infection who met the inclusion criteria were included in the present analysis. The mean age of patients was $63.4 \pm 17.56(46.2 \%)$ patients were male and $28(53.8 \%)$ patients were female. According to echocardiographic results, 50 patients had diastolic dysfunction, of which 34 (65.4\%) had grade 1 dysfunction (Fig. 1a,b), 14 (26.9\%) patients had grade 2 dysfunction (Fig. 1c,d), and 2 (3.8\%) patients had grade 3 dysfunction (Fig. 1e,f). The mean level of NT-proBNP in these patients was $5001.31 \pm 2899.34$ with the median of 1371 ( $24647-473.75)$. The demographic and baseline characteristics of the studied patients are presented in Table 1. 
Table 1

Baseline characteristics of total and different degrees of NT-proBNP

\begin{tabular}{|c|c|c|c|c|c|}
\hline WithoutDD $(n=2)$ & $\begin{array}{l}\text { gradeDD1(n } \\
=34)\end{array}$ & $\begin{array}{l}\text { gradeDD2(n } \\
=14)\end{array}$ & $\begin{array}{l}\text { gradeDD3(n } \\
=2\end{array}$ & $N=52$ & \\
\hline Male/Female (n) & $1 / 1$ & $16 / 18$ & $6 / 8$ & $1 / 1$ & $24 / 28$ \\
\hline Age (years) & 34 & $62 \pm 17.92$ & $68.5 \pm 14.29$ & $76 \pm 14.14$ & $63.4 \pm 17.56$ \\
\hline History of HTN (n) & 0 & $12(42.9)$ & $6(60)$ & $1(50)$ & $19(36.5 \%)$ \\
\hline History of DM (n) & 0 & $9(31)$ & $4(40)$ & $1(50)$ & $14(26.9 \%)$ \\
\hline $\begin{array}{l}\text { Serum NT-proBNP } \\
\text { )pg/Ml( }\end{array}$ & $\begin{array}{l}963.5 \pm \\
942.57\end{array}$ & $\begin{array}{l}1344.96 \pm \\
1375.5\end{array}$ & $\begin{array}{l}5391.57 \pm \\
7031.89\end{array}$ & $\begin{array}{l}13814 \pm \\
12436.59\end{array}$ & $\begin{array}{l}2899.34 \pm \\
5001.31\end{array}$ \\
\hline Creatinine (mg/dl) & $5.3 \pm 6.5$ & $1.74 \pm 2.5$ & $3.64 \pm 3.42$ & $4.4 \pm 2.96$ & $2.48 \pm 3.02$ \\
\hline WBC (109 /L) & $\begin{array}{l}13500 \pm \\
5091.16\end{array}$ & $\begin{array}{l}8091.52 \pm \\
3442.31\end{array}$ & $\begin{array}{l}8600 \pm \\
3776.24\end{array}$ & $\begin{array}{l}9650 \pm \\
1202.08\end{array}$ & $\begin{array}{l}8606.40 \pm \\
3597.78\end{array}$ \\
\hline LYM (109 /L) & $11.5 \pm 2.82$ & $10.31 \pm 8.03$ & $8.81 \pm 8.76$ & $4.15 \pm 0.07$ & $9.74 \pm 7.69$ \\
\hline $\mathrm{Neu}$ & $82.32 \pm 0.59$ & $\begin{array}{l}49.35 \pm \\
38.41\end{array}$ & $\begin{array}{l}38.85 \pm \\
42.01\end{array}$ & $\begin{array}{l}45.26 \pm \\
62.69\end{array}$ & $49.19 \pm 38.77$ \\
\hline $\mathrm{CRP}(\mathrm{mg} / \mathrm{L})$ & - & $75.28 \pm 70.3$ & $114 \pm 96.16$ & 29 & $76.84 \pm 70.12$ \\
\hline $\mathrm{Hb}$ & $14.3 \pm 3.81$ & $11.24 \pm 1.82$ & $10.42 \pm 1.54$ & 8.8 & $11.15 \pm 2.05$ \\
\hline BUN & 16 & $\begin{array}{l}29.34 \pm \\
20.11\end{array}$ & $\begin{array}{l}46.71 \pm \\
36.97\end{array}$ & $75 \pm 38.18$ & $35.39 \pm 27.27$ \\
\hline $\mathrm{Na}$ & 135 & $134.6 \pm 3.4$ & $136.5 \pm 5.35$ & $133.5 \pm 7.77$ & $134.9 \pm 3.93$ \\
\hline k & 3.7 & $4.18 \pm 0.67$ & $4.4 \pm 0.61$ & $5.3 \pm 1.97$ & $4.28 \pm 0.76$ \\
\hline IL-6 & $10.4 \pm 3.95$ & $\begin{array}{l}78.48 \pm \\
143.91\end{array}$ & $15.8 \pm 8.9$ & - & $\begin{array}{l}64.71 \pm \\
129.87\end{array}$ \\
\hline D-dimer & $\begin{array}{l}1249 \pm \\
345.06\end{array}$ & $\begin{array}{l}1046.82 \pm \\
1249.70\end{array}$ & $\begin{array}{l}481.75 \pm \\
680.56\end{array}$ & - & $\begin{array}{l}1010.53 \pm \\
1140.23\end{array}$ \\
\hline $\begin{array}{l}\text { Procalcitonin } \\
\text { (PCT) }\end{array}$ & 0.16 & $0.18 \pm 0.17$ & $0.46 \pm 0.4$ & $44.4 \pm 57.41$ & $4.88 \pm 19.41$ \\
\hline o2sat & $94.5 \pm 0.7$ & $94.41 \pm 3.44$ & $90.35 \pm 4.18$ & $86.5 \pm 2.12$ & $93.01 \pm 4.15$ \\
\hline $\begin{array}{l}\text { In-hospital death } \\
\text { (n) }\end{array}$ & 0 & $2(5.9)$ & $3(21.4)$ & $2(100)$ & $7(13.5 \%)$ \\
\hline
\end{tabular}




\begin{tabular}{|c|c|c|c|c|c|}
\hline WithoutDD $(n=2)$ & $\begin{array}{l}\text { gradeDD1(n } \\
=34)\end{array}$ & $\begin{array}{l}\text { gradeDD2(n } \\
=14)\end{array}$ & $\begin{array}{l}\text { gradeDD3(n } \\
=2\end{array}$ & $N=52$ & \\
\hline Male/Female (n) & $1 / 1$ & $16 / 18$ & $6 / 8$ & $1 / 1$ & $24 / 28$ \\
\hline Age (years) & 34 & $62 \pm 17.92$ & $68.5 \pm 14.29$ & $76 \pm 14.14$ & $63.4 \pm 17.56$ \\
\hline History of HTN (n) & 0 & $12(42.9)$ & $6(60)$ & $1(50)$ & $19(36.5 \%)$ \\
\hline History of DM (n) & 0 & $9(31)$ & $4(40)$ & $1(50)$ & $14(26.9 \%)$ \\
\hline $\begin{array}{l}\text { Serum NT-proBNP } \\
\text { )pg/Ml( }\end{array}$ & $\begin{array}{l}963.5 \pm \\
942.57\end{array}$ & $\begin{array}{l}1344.96 \pm \\
1375.5\end{array}$ & $\begin{array}{l}5391.57 \pm \\
7031.89\end{array}$ & $\begin{array}{l}13814 \pm \\
12436.59\end{array}$ & $\begin{array}{l}2899.34 \pm \\
5001.31\end{array}$ \\
\hline Creatinine (mg/dl) & $5.3 \pm 6.5$ & $1.74 \pm 2.5$ & $3.64 \pm 3.42$ & $4.4 \pm 2.96$ & $2.48 \pm 3.02$ \\
\hline WBC (109 /L) & $\begin{array}{l}13500 \pm \\
5091.16\end{array}$ & $\begin{array}{l}8091.52 \pm \\
3442.31\end{array}$ & $\begin{array}{l}8600 \pm \\
3776.24\end{array}$ & $\begin{array}{l}9650 \pm \\
1202.08\end{array}$ & $\begin{array}{l}8606.40 \pm \\
3597.78\end{array}$ \\
\hline LYM (109 /L) & $11.5 \pm 2.82$ & $10.31 \pm 8.03$ & $8.81 \pm 8.76$ & $4.15 \pm 0.07$ & $9.74 \pm 7.69$ \\
\hline $\mathrm{Neu}$ & $82.32 \pm 0.59$ & $\begin{array}{l}49.35 \pm \\
38.41\end{array}$ & $\begin{array}{l}38.85 \pm \\
42.01\end{array}$ & $\begin{array}{l}45.26 \pm \\
62.69\end{array}$ & $49.19 \pm 38.77$ \\
\hline $\mathrm{CRP}(\mathrm{mg} / \mathrm{L})$ & - & $75.28 \pm 70.3$ & $114 \pm 96.16$ & 29 & $76.84 \pm 70.12$ \\
\hline $\mathrm{Hb}$ & $14.3 \pm 3.81$ & $11.24 \pm 1.82$ & $10.42 \pm 1.54$ & 8.8 & $11.15 \pm 2.05$ \\
\hline BUN & 16 & $\begin{array}{l}29.34 \pm \\
20.11\end{array}$ & $\begin{array}{l}46.71 \pm \\
36.97\end{array}$ & $75 \pm 38.18$ & $35.39 \pm 27.27$ \\
\hline $\mathrm{Na}$ & 135 & $134.6 \pm 3.4$ & $136.5 \pm 5.35$ & $133.5 \pm 7.77$ & $134.9 \pm 3.93$ \\
\hline k & 3.7 & $4.18 \pm 0.67$ & $4.4 \pm 0.61$ & $5.3 \pm 1.97$ & $4.28 \pm 0.76$ \\
\hline IL-6 & $10.4 \pm 3.95$ & $\begin{array}{l}78.48 \pm \\
143.91\end{array}$ & $15.8 \pm 8.9$ & - & $\begin{array}{l}64.71 \pm \\
129.87\end{array}$ \\
\hline D-dimer & $\begin{array}{l}1249 \pm \\
345.06\end{array}$ & $\begin{array}{l}1046.82 \pm \\
1249.70\end{array}$ & $\begin{array}{l}481.75 \pm \\
680.56\end{array}$ & - & $\begin{array}{l}1010.53 \pm \\
1140.23\end{array}$ \\
\hline $\begin{array}{l}\text { Procalcitonin } \\
\text { (PCT) }\end{array}$ & 0.16 & $0.18 \pm 0.17$ & $0.46 \pm 0.4$ & $44.4 \pm 57.41$ & $4.88 \pm 19.41$ \\
\hline o2sat & $94.5 \pm 0.7$ & $94.41 \pm 3.44$ & $90.35 \pm 4.18$ & $86.5 \pm 2.12$ & $93.01 \pm 4.15$ \\
\hline $\begin{array}{l}\text { In-hospital death } \\
\text { (n) }\end{array}$ & 0 & $2(5.9)$ & $3(21.4)$ & $2(100)$ & $7(13.5 \%)$ \\
\hline
\end{tabular}

Mean serum proBNP levels increased with increasing grade of diastolic dysfunction. Table 2 compares the mean serum level of proBNP in terms of the diastolic dysfunction grade. There was a correlation between proBNP level and some echocardiographic parameters and the relationship between serum proBNP level and these indices was positive. Among the echocardiographic parameters with a positive correlation with proBNP, the severity of the correlation was related to RA_size $(r=0.61, p=0.0001)$, LVED 
$(r=0.45, p=0.0008), L V_{-} E / e^{\prime}(r=0.27, p=0.05), \operatorname{LV} \_E(r=0.35, p=0.01)$, respectively. Among the echocardiographic parameters, left ventricular ejection fraction (LVEF) $(r=-0.43, p=0.0012)$ had a significant and negative correlation with serum NT-proBNP level.

Table 2

Relationship between NT-proBNP levels and echocardiographic parameters

\begin{tabular}{|lll|}
\hline Echo Parameters (left) & Pearson correlation coefficient & P-value \\
\hline LVED & 0.45 & 0.0006 \\
RVEDd & 0.02 & 0.84 \\
\hline LAsize & 0.1 & 0.47 \\
\hline TAPSE & -0.13 & 0.34 \\
\hline LVEF & -0.43 & 0.0012 \\
SPAP & -0.44 & 0.12 \\
\hline LV_E & 0.35 & 0.01 \\
\hline LV_A & 0.01 & 0.89 \\
\hline LV_E/A & -0.03 & 0.82 \\
\hline LV_E/e' & 0.27 & 0.05 \\
\hline RV_E & 0.07 & 0.58 \\
\hline RV_A & -0.05 & 0.73 \\
\hline RV_E/A & 0.01 & 0.93 \\
\hline RV_E/e' & -0.16 & 0.25 \\
\hline RA_size & 0.61 & 0.0001 \\
\hline IVC_size & 0.18 & 0.46 \\
\hline
\end{tabular}

The cut-off point as a predictor of grade 2 and 3 diastolic dysfunction for NT-proBNP level was 799 $\mathrm{pg} / \mathrm{mL}$ with $100 \%$ sensitivity and $52.78 \%$ specificity (Fig. 2a). The area under the curve for this cut-off point was $\left(A U C=0.81\right.$.). Among the echocardiographic parameters, $L V \_E>50 \mathrm{~cm}$ at the cut-off point NTproBNP $=1479 \mathrm{pg} / \mathrm{mL}$, had an acceptable area under curve and a favorable predictive value $(\mathrm{AUC}=0.66$, $P P V=100)(F i g .2 b)$ as well as the echocardiographic parameter RV_E/A $>2$ at the cut-off point NTproBNP $=556 \mathrm{pg} / \mathrm{mL}$, had an acceptable area under curve and a good predictive value $(\mathrm{AUC}=0.71, \mathrm{PPV}=$ 97.2) (Fig. 2c) (Table 3). 
Table 3

AUC, sensitivity, specificity, and positive and negative predictive values by NT-proBNP at a cut off-value

\begin{tabular}{|c|c|c|c|c|c|c|}
\hline Parameter* & $\begin{array}{l}\text { Cut-off value NT- } \\
\text { proBNP }\end{array}$ & $\begin{array}{l}\text { AUC }(95 \% \\
\text { Cl) }\end{array}$ & $\begin{array}{l}\text { Sensitivity } \\
\text { (\%) }\end{array}$ & $\begin{array}{l}\text { Specificity } \\
(\%)\end{array}$ & $\begin{array}{l}\text { PPV } \\
(\%)\end{array}$ & $\begin{array}{l}\text { NPV } \\
(\%)\end{array}$ \\
\hline $\begin{array}{l}\text { Diastolic } \\
\text { dysfunction }\end{array}$ & 799 & $\begin{array}{l}0.81(0.7- \\
0.93)\end{array}$ & 100 & 52.78 & 48.5 & 100 \\
\hline \multicolumn{7}{|l|}{ Grade2,3 } \\
\hline LVEDD & 1736 & $\begin{array}{l}0.60(0.4- \\
0.81)\end{array}$ & 63.64 & 65.85 & 33.3 & 87.1 \\
\hline LA size & 587 & $\begin{array}{l}0.63(0.39- \\
0.88)\end{array}$ & 100 & 34.7 & 16.7 & 100 \\
\hline TAPSE $<1 / 7$ & 1140 & $\begin{array}{l}0.77(0.60- \\
0.94)\end{array}$ & 100 & 52.17 & 21.4 & 100 \\
\hline TAPSE $<2 / 4$ & 805 & $\begin{array}{l}0.50(0.32- \\
0.68)\end{array}$ & 81.82 & 43.9 & 28.1 & 90 \\
\hline SPAP & 1497 & $\begin{array}{l}0.68(0.52- \\
0.84)\end{array}$ & 65 & 70 & 59.1 & 75 \\
\hline LV_E & 1479 & $\begin{array}{l}0.66(0.5- \\
0.83)\end{array}$ & 53.33 & 100 & 100 & 25 \\
\hline LV_EA $>0 / 8$ & 1630 & $\begin{array}{l}0.55(0.39- \\
0.71)\end{array}$ & $51 / 72$ & $71 / 43$ & 71.4 & 51.7 \\
\hline LV_EA $>2$ & 955 & $\begin{array}{l}0.62(0.42- \\
0.82)\end{array}$ & 80 & 47.5 & 27.6 & 90.5 \\
\hline LV_E/e ${ }^{\prime}$ & 150 & $\begin{array}{l}0.64(0.48- \\
0.80)\end{array}$ & 57.89 & 72.73 & 75 & 56.6 \\
\hline $\mathrm{RV} \_\mathrm{E} / \mathrm{A}>0 \_0.8$ & 1850 & $\begin{array}{l}0.53(0.35- \\
0.70)\end{array}$ & 52.17 & 75 & 63.2 & 65.6 \\
\hline $\mathrm{RV} \_\mathrm{E} / \mathrm{A}>2$ & 556 & $\begin{array}{l}0.71(0.43- \\
0.99)\end{array}$ & 74.47 & 75 & 97.2 & 20 \\
\hline$>4 R V_{-} E / e^{\prime}$ & 556 & $\begin{array}{l}0.51(0.34- \\
0.69)\end{array}$ & 76.67 & 38.1 & 63.9 & 53.3 \\
\hline RV_E/e $>6$ & 556 & $\begin{array}{l}0.49(0.30- \\
0.68)\end{array}$ & 81.82 & 32.5 & 25 & 86.7 \\
\hline Pericardial_effusion & 488 & $\begin{array}{l}0.46(.12- \\
0.81)\end{array}$ & 100 & 27.08 & 10.3 & 100 \\
\hline
\end{tabular}

After multivariate logistic regression analysis, those with a serum pro BNP level equal and above 799 had a 37 times higher chance of diastolic dysfunction than those with a serum pro BNP level below $799 \mathrm{E}$ 
$(\mathrm{OR}=37.16, \mathrm{p}=0.04)$. All echocardiographic parameters were evaluated by logistic regression model and only SPAP and LV_E were significant compared to other indices so that for every unit of increase in SPAP, the chance of diastolic dysfunction increases by $22 \%(O R=1.22, p=0.01)$. For each unit of increase in LV_E, the chance of diastolic dysfunction increases by $16 \%(O R=1.16, p=0.01)$ (Table 4).

Table 4

multivariable logistic regression for evaluating the ability of NT-proBNP to identify diastolic dysfunction when compared with other indicators

\begin{tabular}{|llll|}
\hline indicator & OR & P-value & $95 \% \mathrm{Cl}$ \\
\hline NT_proBNP & 37.16 & 0.04 & $1.12-1231.48$ \\
$>=799$ & & & \\
\hline SPAP & 1.22 & 0.01 & $1.03-1.45$ \\
\hline LV_E & 1.16 & 0.01 & $1.02-1.32$ \\
\hline
\end{tabular}

\section{Discussion}

The study aimed to evaluate the relationship between NT-proBNP levels and left ventricular diastolic dysfunction in patients with COVID-19. Our study showed that plasma NT-proBNP levels in patients with increased diastolic dysfunction was related to the severity of the disease so that with increasing severity of diastolic dysfunction, proBNP levels also increase. It was also found that the cut-off point of NTproBNP $=799 \mathrm{pg} / \mathrm{mL}$ could be used as a predictor of diastolic dysfunction grades 2 and 3 . A person with COVID-19 who has high-grade diastolic dysfunction is $100 \%$ likely to have a serum proBNP level above $799 \mathrm{pg} / \mathrm{mL}$. In this study, patients with a serum proBNP level above 799 had a 37 times higher chance of having diastolic dysfunction than those with a serum proBNP level below this amount. There are studies that, like our study, found significantly higher proBNP levels in patients with advanced diastolic dysfunction.

In one study this level was $286 \pm 31 \mathrm{pg} / \mathrm{mL}$ (13), in another study the proBNP level was 46 to $48 \mathrm{pg} / \mathrm{mL}$ above normal (14) and in another study, it was $14 \pm 13 \mathrm{pmol} / \mathrm{l}$ (15). Although these late peptides have been shown to be associated with severe diastolic dysfunction, their role in the diagnosis of mild diastolic heart failure is uncertain (16). In a study on 396 patients that showed a strong association between plasma NT-proBNP levels and the risk of death in COVID-19 patients, the best median NT-proBNP for predicting mortality at 53 days of follow-up was $847.5 \mathrm{pg} / \mathrm{ml}$. According to this study, NT-proBNP was associated with mortality both in the entire study population and after the exclusion of HF patients. NTproBNP above this level was associated with a higher risk of mortality in these patients due to cardiac complications raised by complex interactions between previous conditions, ischemia, systemic inflammation, and direct pathogen damage to the cardiovascular system (17). This amount was lower than the cut-off of our study which predicted grade 2 and 3 diastolic dysfunctions as a poor outcome. 
According to an article published in the European Heart Association in 2016, a cut-off point of 125, along with other anatomical and functional signs, was used to diagnose diastolic heart failure. In COVID-19 patients, Pro-BNP levels cannot be satisfied with the previous standard figures due to the possibility of high levels of infection, inflammation and hypoxia. It seems that a different cut-off point should be considered. Based on the results of this study, NT-proBNP levels above $799 \mathrm{pg} / \mathrm{ml}$ were obtained to diagnose high-grade diastolic dysfunction in patients with severe COVID-19 (18). The sensitivity of NTproBNP for the diagnosis of diastolic dysfunction in our study was $100 \%$ and it was an accurate screening test that in Lu Bien study (13) had a sensitivity of $85 \%$ for the diagnosis of diastolic dysfunction in non-COVID patients, this value in another study was reported to be $69 \%$ and NT-proBNP was not recommended for screening diastolic dysfunction. However, this study was performed on people over 45 living in the community years before the COVID pandemic who were randomly included in the study (19).

In this study, we compared NT-proBNP for the diagnosis of diastolic dysfunction in hospitalized patients with COVID-19 with echocardiographic indices as a routine non-invasive procedure. However, the standard for assessing diastolic heart function is to measure the pressure-volume relationship with a catheter, which is an invasive procedure. In our study, there was a positive correlation between proBNP levels and some echocardiographic parameters including RA_size, LVED, LV_ Ee, and LV_E, and this indicates that as proBNP levels increase, these indices also increase. Significant negative correlation between proBNP level and one of the echocardiographic parameters including LVEF increases with decreasing LVEF serum NT-proBNP level number. According to this study, proBNP above $556 \mathrm{pg} / \mathrm{ml}$ in severe COVID-19 patients has a predictive value of $97.2 \%$ for the presence of RV_EA $>2$ and also proBNP above $556 \mathrm{pg} / \mathrm{ml}$ in these patients has a predictive value of $63.9 \%$ for the presence of LV_Ee $>4$ in echocardiography. These two echocardiographic parameters indicate an increase in right heart filling pressures and due to the relationship between right heart pressure and left heart filling pressures and its relationship with pulmonary pressure, hypoxia and lung pressures, it seems that diastolic dysfunction of the right side of the heart begins at lower levels of proBNP.

According to other results from this study, if a person has a proBNP above $1479 \mathrm{pg} / \mathrm{ml}, \mathrm{LV}$ _E would be greater than $50 \mathrm{~cm}$ for $100 \%$ (E wave velocity above 50 ). Given that the E-wave velocity showed a compression gradient between the atrium and the ventricle and depend on left ventricular complication and left ventricular pressure, it could be said that proBNP above $1479 \mathrm{pg} / \mathrm{ml}$ should avoid volumetric and compressive overload. In this study, for every unit increase in SPAP, the chance of diastolic dysfunction increased by $22 \%$. SPAP levels are associated with inflammation and hypoxia of the lungs and are also associated with increased and limited left-filling pressures. The limitations of this study included it was an observational, single-center study with the inherent limitations of this type of design. The number of samples and the possibility of performing echocardiography were limited due to policies focused on prevention of SARS-CoV-2 transmission.

\section{Conclusion}


briefly, these data suggested that elevated NT-proBNP levels were associated with grade 2 or higher grade of diastolic dysfunction in patients with COVID-19, and this result suggested that this method could be used as a predictor of diastolic dysfunction in these patients, and better understanding of the possibility of increased right heart filling pressures. Following this result, by estimating the probability of increased left and right filling pressures of the heart by reaching the level of NT-proBNP above a certain number, excessive flow of fluids without considering the need and urine output and calculating the estimated filling pressures of the heart can be prevented. In addition, the results of this study indicated a new direction for further research on the use of NT-proBNP as a non-invasive method of diagnosing diastolic dysfunction in COVID-19 patients. It was recommended to investigate the levels of NT-proBNP associated with diastolic dysfunction in higher sample size and multicenter studies. Of course, the follow-up of these patients is valuable in terms of the persistence of diastolic failure and pulmonary pressure.

\section{Abbreviations}

COVID-19: Coronavirus disease 2019; CT: computed tomography; LVEF: left ventricular ejection fraction; SARS-CoV-2: Severe acute respiratory syndrome coronavirus 2; N-terminal pro-brain natriuretic peptide (NT-proBNP).

\section{Declarations}

\section{Ethics approval and consent to participate}

Not applicable.

\section{Consent to publish}

Written informed consent was obtained from the patients. We assure that a copy of the consent form is available for review by the journal upon request.

\section{Availability of data and material}

Please contact the corresponding author for data requests.

\section{Competing interests}

The authors declare that they have no competing interests.

\section{Funding/Support}

Not applicable.

\section{Authors' contributions}


SS coordinated the study; KE, SGZ, MC, PAM, and RP were responsible for data collection. NZ analyzed and interpreted the data. All authors provided comments on the manuscript at various stages of development. All authors read and approved the final manuscript.

\section{Acknowledgments:}

The authors thank the Clinical Research Development Unit of Rouhani Hospital. The authors also appreciate Farhad Seif for his kind contribution to the final revision of the manuscript.

\section{References}

1. Seif F, Aazami H, Khoshmirsafa M, Kamali M, Mohsenzadegan M, Pornour M et al (2020) JAK inhibition as a new treatment strategy for patients with COVID-19. Int Arch Allergy Immunol 181(6):467-475

2. Nemati R, Ganjoo M, Jadidi F, Tanha A, Baghbani R. Electrocardiography in early diagnosis of cardiovascular complications of covid-19; a systematic literature review. Archives of academic emergency medicine. 2021;9(1)

3. Roshanravan N, Seif F, Ostadrahimi A, Pouraghaei M, Ghaffari S (2020) Targeting cytokine storm to manage patients with COVID-19: a mini-review. Archives of Medical Research

4. Corrales-Medina VF, Suh KN, Rose G, Chirinos JA, Doucette S, Cameron DW et al (2011) Cardiac complications in patients with community-acquired pneumonia: a systematic review and metaanalysis of observational studies. PLoS Med 8(6):e1001048

5. Freaney PM, Shah SJ, Khan SS (2020) COVID-19 and heart failure with preserved ejection fraction. Jama 324(15):1499-1500

6. Cardiology E. ESC Guidance for the Diagnosis and Management of CV Disease during the COVID-19 Pandemic. 2020

7. Skulstad H, Cosyns B, Popescu BA, Galderisi M, Salvo GD, Donal E et al (2020) COVID-19 pandemic and cardiac imaging: EACVI recommendations on precautions, indications, prioritization, and protection for patients and healthcare personnel. European Heart Journal-Cardiovascular Imaging 21(6):592-598

8. Zhang Y, Coats AJ, Zheng Z, Adamo M, Ambrosio G, Anker SD et al (2020) Management of heart failure patients with COVID-19: a joint position paper of the Chinese Heart Failure Association \& National Heart Failure Committee and the Heart Failure Association of the European Society of Cardiology. Eur J Heart Fail 22(6):941-956

9. Mueller C, McDonald K, de Boer RA, Maisel A, Cleland JG, Kozhuharov N et al (2019) Heart Failure Association of the European Society of Cardiology practical guidance on the use of natriuretic peptide concentrations. Eur J Heart Fail 21(6):715-731

10. Myhre PL, Vaduganathan M, O'Meara E, Claggett BL, de Denus S, Jarolim P et al (2020) Mechanistic effects of spironolactone on cardiovascular and renal biomarkers in heart failure with preserved 
ejection fraction: a TOPCAT biorepository study. Circulation: Heart Failure 13(1):e006638

11. Volpe M, Rubattu S, Burnett J Jr (2014) Natriuretic peptides in cardiovascular diseases: current use and perspectives. European heart journal 35(7):419-425

12. Chitsazan M, Amin A, Chitsazan M, Ziaie N, Amri Maleh P, Pouraliakbar H et al (2021) Heart failure with preserved ejection fraction in coronavirus disease 2019 patients: the promising role of diuretic therapy in critically ill patients. ESC Heart Failure 8(2):1610-1614

13. Lubien E, DeMaria A, Krishnaswamy P, Clopton P, Koon J, Kazanegra R et al (2002) Utility of Bnatriuretic peptide in detecting diastolic dysfunction: comparison with Doppler velocity recordings. Circulation 105(5):595-601

14. Mottram PM, Leano R, Marwick TH (2003) Usefulness of B-type natriuretic peptide in hypertensive patients with exertional dyspnea and normal left ventricular ejection fraction and correlation with new echocardiographic indexes of systolic and diastolic function. The American journal of cardiology 92(12):1434-1438

15. Alehagen U, Eriksson H, Nylander E, Dahlström U (2002) Heart failure in the elderly: characteristics of a Swedish primary health care population. Heart Drug 2(5):211-220

16. Bibbins-Domingo K, Ansari M, Schiller NB, Massie B, Whooley MA (2004) Is B-type natriuretic peptide a useful screening test for systolic or diastolic dysfunction in patients with coronary disease? Data from the Heart and Soul Study. Am J Med 116(8):509-516

17. Caro-Codón J, Rey JR, Buño A, Iniesta AM, Rosillo SO, Castrejon-Castrejon S et al (2021) Characterization of NT-proBNP in a large cohort of COVID-19 patients. Eur J Heart Fail 23(3):456464

18. McMurray J, Adamopoulos S, Anker SD, Auricchio A, Böhm M, Dickstein K et al. Task Force for the Diagnosis and Treatment of Acute and Chronic Heart Failure 2012 of the European Society of Cardiology; ESC Committee for Practice Guidelines. ESC guidelines for the diagnosis and treatment of acute and chronic heart failure 2012: The Task Force for the Diagnosis and Treatment of Acute and Chronic Heart Failure 2012 of the European Society of Cardiology. Developed in collaboration with the Heart Failure Association (HFA) of the ESC. Eur J Heart Fail. 2012;14(8):803-869

19. Redfield MM, Rodeheffer RJ, Jacobsen SJ, Mahoney DW, Bailey KR, Burnett JC Jr (2004) Plasma brain natriuretic peptide to detect preclinical ventricular systolic or diastolic dysfunction: a community-based study. Circulation 109(25):3176-3181

\section{Figures}



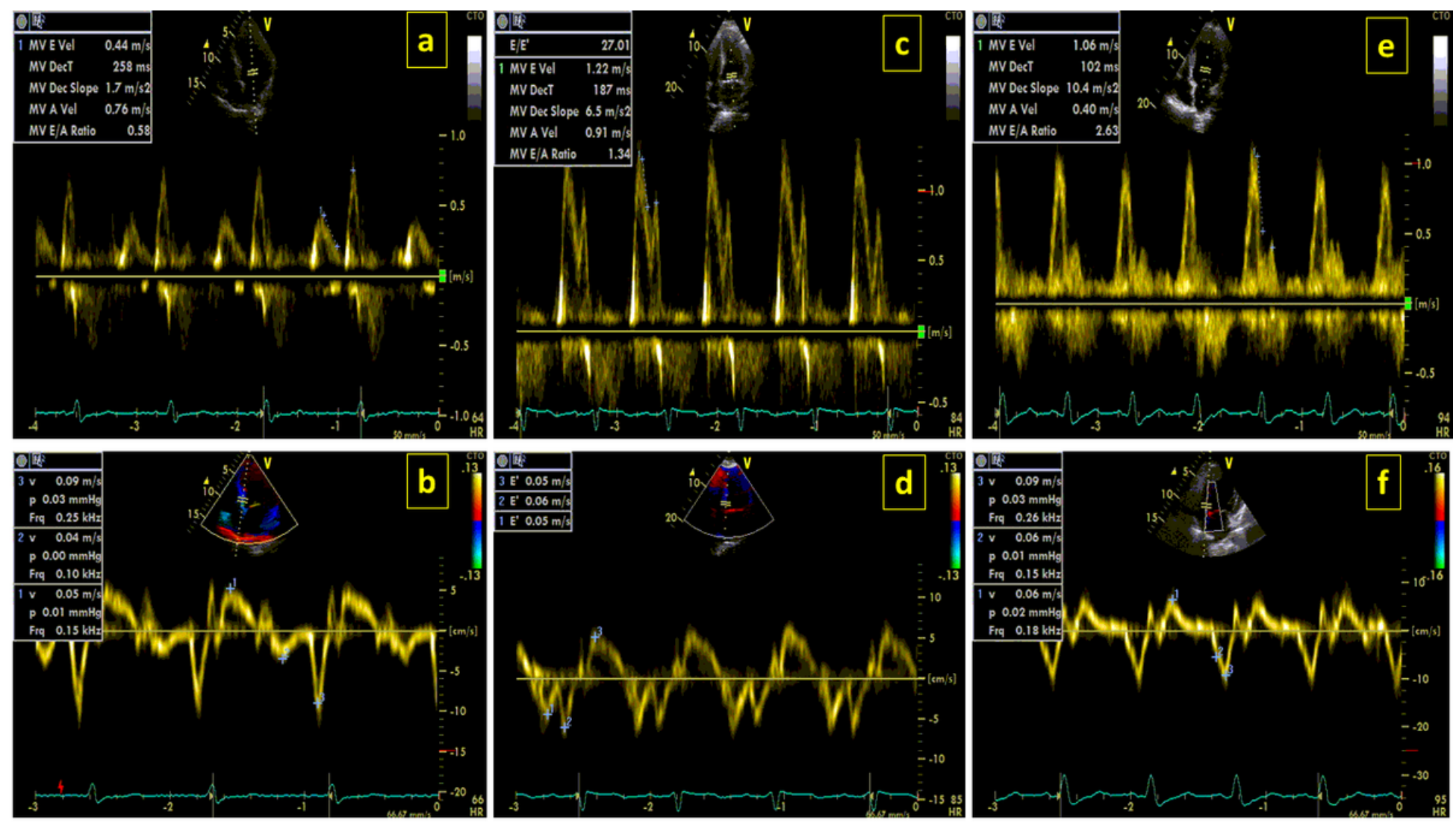

\section{Figure 1}

Grading of diastolic dysfunction. a,b- Grade 1, c,d-Grade 2, e,f- Grade 3.
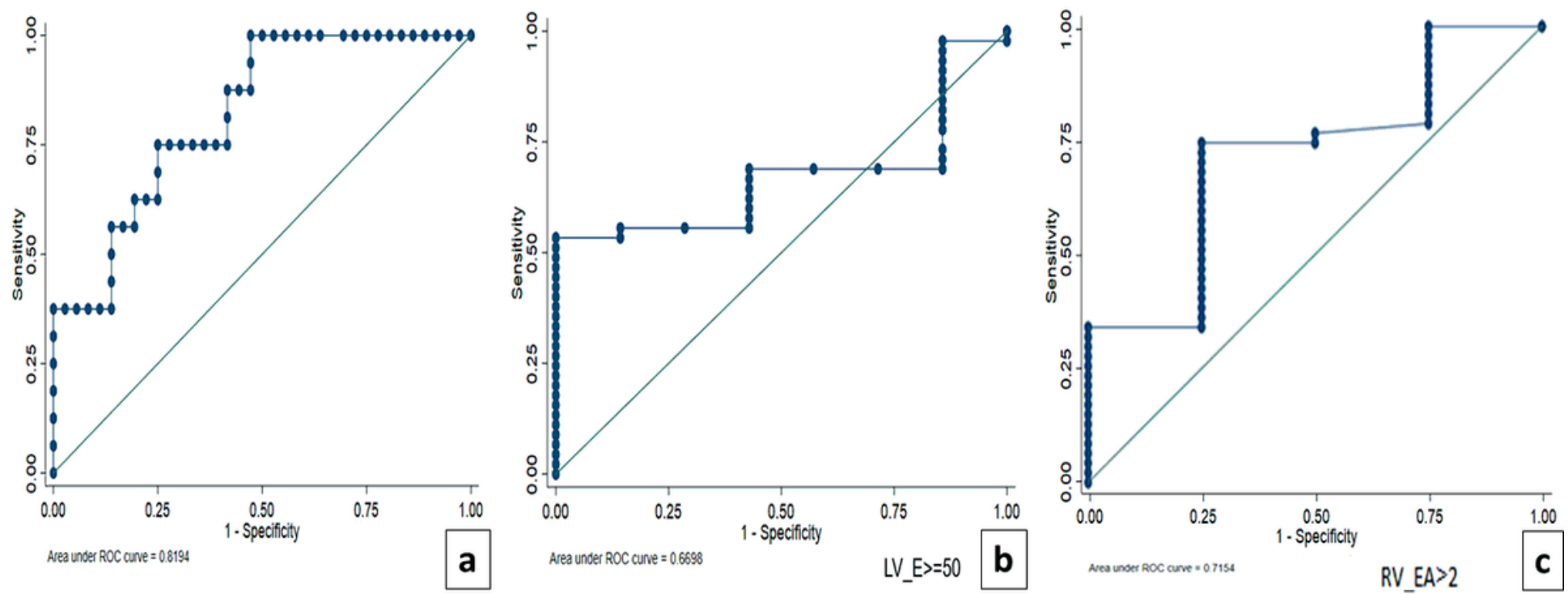

Figure 2

a- ROC curve for predicting cutoff value of NT-proBNP for diastolic dysfunction. Area under the curve was $0.81 \%$. b- ROC curve for predicting cutoff value of LV_E>50. Area under the curve was $0.67 \%$. C- ROC curve for predicting cutoff value of RV_EA $<2$. Area under the curve was $0.71 \%$. 